\title{
The Role of Lipids on Sorption Characteristics of Freshwater- and Wastewater-Irrigated Soils
}

\author{
Yaron Drori, Buuan Lam, Andre Simpson, Zeev Aizenshtat, and Benny Chefetz*
}

\begin{abstract}
The soil lipid fraction can play an important role in the sorption of organic compounds. In this study, the impact of the lipid fraction of freshwater- and wastewater-irrigated soils on the sorption of non- and relatively polar compounds was assessed. Lipid analyses revealed a clear difference between the two lipid fractions. The lipid extract from the wastewater-irrigated soil was consistent with mainly straight paraffinic chain materials; the lipid extract from freshwater-irrigated soil, on the other hand, exhibited stronger signals of aromatics, double bonds, ester, ether, and methyl, in addition to a smaller contribution from methylene protons. Our data suggest that lipid removal induced a stronger increase in the soil's sorption affinity for solutes capable of polar interactions such as atrazine (2-chloro-4-ethylamino-6-isopropylamino-1,3,5-triazine) and chlorotoluron $\left(N^{\prime}\right.$-(3-chloro-4-methylphenyl)- $\mathrm{N}, \mathrm{N}$-dimethylurea) as compared to phenanthrene. Moreover, the level of increase in sorption affinities due to lipid removal was much higher for the freshwater-irrigated soil than for its wastewater-irrigated counterpart, even though the level of lipids in the freshwater-irrigated soil was half that in the wastewater-irrigated one (6 vs. $11 \%$ of the total organic C). The higher level of polar functionalities, such as ether and ester moieties, in the lipid fraction from the freshwater-irrigated soil suggests that these extractable compounds compete successfully with the polar solutes (atrazine and chlorotoluron) for specific binding sites in the soil organic matter (SOM). It appears that the composition of the lipid fraction may be a key consideration in unraveling the sorption of organic molecules in soils.
\end{abstract}

$\mathrm{S}$ OIL ORGANIC MATTER consists mainly of plant residues, materials derived from them via decomposition processes, microbial tissues, and humic substances (Zech et al., 1997). In agricultural soils, lipids make up between 0.2 and $5 \%$ of the total SOM (Stevenson, 1994). The soil lipid fraction is defined as the water-insoluble organic matter that can be solubilized and extracted from soils using nonpolar organic solvents such as hexane, benzene, chloroform, ether, and others. The lipid fraction of SOM is derived from degradation products of plant materials (mainly from aerial and subaerial cuticular matter) and microorganisms (Bull et al., 2000; Naafsa et al., 2004) and includes fatty acids, sterols, terpenes, long-chain hydrocarbons, chlorophyll, fats, waxes, and resins (Stevenson, 1994; Jandi et al., 2002). The mo-

Y. Drori and B. Chefetz, Department of Soil and Water Sciences, Faculty of Agricultural, Food and Environmental Quality Sciences, The Hebrew University of Jerusalem, P.O. Box 12, Rehovot 76100, Israel. Z. Aizenshtat, Casali Institute of Applied Chemistry and The Institute of Chemistry, The Hebrew University of Jerusalem, Jerusalem 91904, Israel. B. Lam and A. Simpson, Department of Physical and Environmental Science, The University of Toronto at Scarborough, 1265 Military Trail, Toronto, Ontario, MIC 1A4 Canada. Received 8 Jan. 2006.*Corresponding author (chefetz@agri.huji.ac.il).

Published in J. Environ. Qual. 口: $\mathbf{\square - \square}$ (2006).

Technical Reports: Organic Compounds in the Environment doi:10.2134/jeq2006.0013

(c) ASA, CSSA, SSSA

677 S. Segoe Rd., Madison, WI 53711 USA lecular fingerprint or "profile" in the lipid extract (e.g., $\mathrm{C}$-chain length, dominant $\mathrm{C}$, and the distribution of odd and even $\mathrm{C}$ chains) is used to reveal the origin of lipids in the soil. Strong odd-to-even $\mathrm{C}$ ratios of $n$-alkanes are usually assigned to plant-derived epicuticular waxes, whereas $n$-alkanes from bacterial and fungal activities typically exhibit similar levels of odd and even $C$ chain (Stevenson, 1994; Nguyen et al., 2003). Therefore, a higher even/odd ratio of $\mathrm{C}_{4}-\mathrm{C}_{26}$ fatty acids suggests microbial origin, whereas fatty acids exhibiting a dominant fraction of $\mathrm{C}_{26}-\mathrm{C}_{38}$ originate from vascular plants (Schnitzer et al., 1986).

Due to the strong hydrophobic nature of the soil lipids, these materials have been shown to affect the sorption-desorption behavior of hydrophobic organic compounds (HOCs) in soils and sediments. Free extractable lipids can compete with HOCs for hydrophobic sorption sites within the SOM and affect their sorption affinity (Tremblay et al., 2005). On the other hand, Grathwohl (1990) suggested that due to the high hydrophobicity of this fraction, it could also behave as a partitioning domain in soil and sorb HOCs. In addition, Kohl and Rice (1999) and Kohl et al. (2000) suggested that soil lipids are responsible for the linear sorption of polycyclic aromatic hydrocarbons by SOM.

Long-term irrigation with reclaimed wastewater can affect the physical and chemical properties of the soil, as well as the amount and properties of SOM (Guichet et al., 1991; Gonzalez-Vila et al., 1995; Tarchitzky et al., 1999; Friedel et al., 2000). The chemical alteration of the SOM due to long-term irrigation with reclaimed wastewater is influenced mainly by the nature of the applied dissolved organic matter. Guichet et al. (1991) reported that irrigation with wastewater enriched with low-molecular-weight dissolved organic matter significantly increases the amount of SOM. In addition, a relative enrichment of lipids, polysaccharides, and plant residues was observed in the wastewater-irrigated plots. In another report, changes in the chemical properties of fulvic acid were obtained after irrigation with wastewater (Boyd and Sommers, 1990). Gonzalez-Vila et al. (1995) reported that irrigation with olive-mill effluents increases and alters the composition of the soil lipid fraction. Oleic acid (the major component of olive oil) and its oxidation derivates dominated the free and bound lipid fractions in the soil, after $3 \mathrm{yr}$ of oil-mill effluent application. In a previous study (Drori et al., 2005), we reported higher sorption potential and lower desorption ability of atrazine with freshwater- vs.

Abbreviations: $\mathrm{Cr}$, reduced concentrations; GC/MS, gas chromatograph/mass spectrometer; HOC, hydrophobic organic compound; $K_{\mathrm{F}}$, Freundlich distribution coefficient; $K_{\mathrm{OC}}$, carbon-normalized distribution coefficient; NMR, nuclear magnetic resonance; SOM, soil organic matter; UCM, unresolved-complex mixture. 
wastewater-irrigated soils. It was suggested that the SOM which was developed in the wastewater-irrigated soils delays or hinders atrazine interactions with sites that are naturally present in these soils. Our hypothesis is that long-term irrigation with reclaimed wastewater influences the level, characteristics, and properties of the soil lipid fraction, which can affect the sorption capabilities of these soils. Therefore, the objectives of this study were to characterize the lipid fraction in wastewater- and freshwater-irrigated soils and to study the role of this SOM fraction in the sorption behavior of HOCs.

\section{MATERIALS AND METHODS}

\section{Soils}

Topsoils (Rhodoxeralf) were sampled from a citrus orchard in Basra, Israel. The soils were sampled from two nearby plots, one which was irrigated with treated wastewater and the other with freshwater. In each plot, samples were collected from four locations ( $20 \mathrm{~cm}$ away from the dripper). The $0-$ to $3-\mathrm{cm}$ organic layer was removed and samples were collected from 3- to $30-\mathrm{cm}$ depths. The four subsamples were combined to form a $10 \mathrm{~kg}$ composite sample. The soils were air-dried and sieved through a $2-\mathrm{mm}$ sieve. Table 1 summarizes the properties and characteristics of the studied soils. The chemical composition of the irrigation water is reported elsewhere (Drori et al., 2005).

\section{Lipid Extraction and Characterization}

Free lipids were extracted from soils (300 g) by Soxhlet extraction with benzene:methanol $(3: 1, \mathrm{v} / \mathrm{v})$ for $16 \mathrm{~h}$. Then, the soils were dried at room temperature and oven-dried at $65^{\circ} \mathrm{C}$. The untreated soils and the lipid-extracted soils were used in sorption experiments. The lipid extracts were filtered (glass filter; GF/A, Whatman, Maidstone, England) and dried under a $\mathrm{N}_{2}$ stream. The lipids were further cleaned up by placing $20 \mathrm{mg}$ of the dried extracts on the top of a microcolumn containing alumina and silica $(1: 4, \mathrm{v} / \mathrm{v})$. Then, the column was flushed with $10 \mathrm{~mL}$ hexane and then by a similar volume of toluene. The hexane and toluene elutions were further concentrated under a $\mathrm{N}_{2}$ stream.

Gas chromatograph/mass spectrometer (GC/MS) analysis was performed using a GC (HP-5890 series II; Agilent, Palo Alto, CA) operated in splitless mode and equipped with a $30-\mathrm{m}$ long capillary column (SIL $24 \mathrm{CB}$ ) with an internal diameter of $0.25 \mathrm{~mm}$. The oven-temperature gradient was $4^{\circ} \mathrm{C} \mathrm{min}$

Table 1. Selected properties of the studied soils.

\begin{tabular}{|c|c|c|}
\hline & $\begin{array}{c}\text { Freshwater- } \\
\text { irrigated soil }\end{array}$ & $\begin{array}{l}\text { Wastewater- } \\
\text { irrigated soil }\end{array}$ \\
\hline Sand, $\% \dagger$ & $80.9 \pm 0.7 \ddagger$ & $79.5 \pm 0.7$ \\
\hline Silt, $\% \dagger$ & $6.3 \pm 0.7$ & $\mathbf{1 . 3} \pm \mathbf{0 . 2}$ \\
\hline Clay, $\% \dagger$ & $\mathbf{1 2 . 8} \pm \mathbf{0 . 0 2}$ & $19.2 \pm 0.5$ \\
\hline Texture $\dagger$ & sandy loam & sandy loam \\
\hline Organic C, \%§ & $0.76 \pm 0.03$ & $0.91 \pm 0.08$ \\
\hline $\mathrm{CaCO}_{3}, \%$ II & $\mathbf{0 . 3} \pm \mathbf{0 . 0 7}$ & $0.2 \pm 0.05$ \\
\hline Cation exchange capacity, cmol $\mathrm{kg}^{-1} \#$ & $12 \pm 0.5$ & $14 \pm 0.02$ \\
\hline Specific surface area, $\mathbf{m}^{2} \mathbf{g}^{-1}+\dagger$ & $47 \pm 1.3$ & $\mathbf{7 2} \pm \mathbf{0 . 7}$ \\
\hline $\mathbf{p H}+\%$ & $7.90 \pm 0.1$ & $8.08 \pm 0.1$ \\
\hline Electrical conductivity, ds $\mathrm{m}^{-1}+$ & $0.94 \pm 0.01$ & $\mathbf{0 . 7 1} \pm \mathbf{0 . 0 0}$ \\
\hline
\end{tabular}

$\dagger$ Gee and Bauder (2002).

+ \pm Standard deviation of three replicates.

$\S$ Nelson and Sommers (1996).

II Loepert and Suarez (1996).

\# Sumner and Miller (1996).

$\dagger \dagger$ Pennel (2002).

$\uparrow+$ Measured in saturated paste. from 50 to $300^{\circ} \mathrm{C}$ with an initial temperature constant for $5 \mathrm{~min}$ and a maximal temperature constant for $20 \mathrm{~min}$. The GC was coupled to a HP-G-1800B quadropole MS (Agilent, Palo Alto, $\mathrm{CA})$ running in electron impact mode with an electron energy of $70 \mathrm{eV}$. The source temperature was $200^{\circ} \mathrm{C}$, the tested mass range was 45 to $450 \mathrm{Da}$ and the scan-time period was $1 \mathrm{~s}$. Peaks were assigned by comparison with the library of the National Institute of Standards and Technology (NIST), by analysis of fragmentation and by comparison with standards.

Nuclear magnetic resonance (NMR) experiments were performed on a Bruker Avance $500 \mathrm{MHz}$ NMR spectrometer (Bruker, Billerica, MA) equipped with a ${ }^{1} \mathrm{H}-\mathrm{BB}-{ }^{13} \mathrm{C} 5 \mathrm{~mm}$ TBI probe. The dried soil lipid extract samples $(30 \mathrm{mg})$ were dissolved in $1 \mathrm{~mL}$ of benzene- $\mathrm{d}_{6} / \mathrm{methanol}^{-\mathrm{d}_{4}}$ at a ratio of $3: 1$. Solution state ${ }^{1} \mathrm{H}$ NMR experiments were performed with 128 scans, a recycle delay of $3 \mathrm{~s}$, and 32768 time-domain points. Diffusion-edited experiments were used with a bipolar pulse longitudinal encode-decode sequence (Wu et al., 1995). Scans (1024) were collected using a $2.5 \mathrm{~ms}, 333 \mathrm{mT} / \mathrm{m}$ sine-shaped gradient pulse, a diffusion time of $200 \mathrm{~ms}, 16000$ time-domain points and a sample temperature of $25^{\circ} \mathrm{C}$; spectra were apodized by multiplication with an exponential decay corresponding to $0.3 \mathrm{~Hz}$ line-broadening in the transformed spectrum, and a zero filling factor of 2 .

\section{Batch Sorption Experiments}

Aqueous solutions of all solutes: atrazine, chlorotoluron, and phenanthrene, were prepared by adding aliquots from a concentrated HPLC-grade methanol stock solution to a background solution containing $10 \mathrm{mM} \mathrm{CaCl} 2$ and $100 \mathrm{mg} \mathrm{L}^{-1}$ $\mathrm{NaN}_{3}$ to maintain a constant ionic strength and to inhibit microbial activity during the experiment, respectively. Methanol concentration was maintained at $<0.1 \%(\mathrm{v} / \mathrm{v})$ to avoid co-solvent effects. Atrazine (98\% purity, Agan Co., Ashdod, Israel) solutions $(25 \mathrm{~mL})$, covering a range of 1 to $20 \mathrm{mg} \mathrm{L}^{-1}$, were added to samples previously weighed into $50-\mathrm{mL}$ Teflon centrifuge tubes (Nalgene, Rochester, NY) with Teflon caps containing $15 \mathrm{~g}$ of soil. Chlorotoluron (98\% purity, Agan Co.) solutions $(15 \mathrm{~mL})$ covering a range of 0.25 to $25 \mathrm{mg} \mathrm{L}^{-1}$ were added to Teflon centrifuge tubes containing $9 \mathrm{~g}$ of soil sample. Phenanthrene (>96\%, Sigma, St. Louis, MO) solutions $(20 \mathrm{~mL})$ in a concentration range of 0.1 to $500 \mu \mathrm{g} \mathrm{L}^{-1}$ were added to $200 \mathrm{mg}$ soil samples previously weighed into $30-\mathrm{mL}$ glass centrifuge tubes (Kimble, Vineland, NJ) with Teflon caps.

In all cases, the sorbent weight was set to maintain 30 to $70 \%$ sorption. Sorption of the analytes to the tubes was found to be negligible $(<0.5 \%)$. Preliminary tests indicated an apparent sorption equilibrium period of $2 \mathrm{~d}$ for the atrazine and $7 \mathrm{~d}$ for the chlorotoluron and phenanthrene. The tubes (three replicates and a blank for each concentration) were agitated end-over-end in the dark at $150 \mathrm{rpm}, 25^{\circ} \mathrm{C}$, for the time period needed to reach equilibrium. Next, the tubes were centrifuged and $10 \mathrm{~mL}$ of the supernatant were removed using a glass pipette and replaced with fresh background solution (sorbatefree). The tubes were then further agitated under the same conditions to perform the desorption step. Supernatants collected from the phenanthrene experiments were diluted 1:1 with methanol to avoid sorption to the HPLC vials. Quantitative HPLC analysis was performed using an L-7100 LaChrom HPLC (Merck-Hitachi, Darmstadt, Germany) with a LiChrospher RP-18 column ( $25 \mathrm{~cm}$ by $4.6 \mathrm{~mm}, 5 \mu \mathrm{m})$ and an isocratic mobile phase of water/acetonitrile (30/70 for atrazine, 40/60 for chlorotoluron, and 15/85 for phenanthrene). Atrazine and chlorotoluron were detected using a photodiode array detector at absorbances of 222 and $248 \mathrm{~nm}$, respectively. Phenanthrene was detected by a fluorescence detector (excitation at 
$244 \mathrm{~nm}$ and emission at $360 \mathrm{~nm}$ ). All sorbates were quantified using external standards.

\section{Data Analysis}

The Freundlich parameters $\left(K_{\mathrm{F}}\right.$ and $\left.N\right)$ were calculated from the logarithmic form of the equation: $q=K_{\mathrm{F}} \times C_{\mathrm{e}}{ }^{N}$, where $q$ is the total sorbed concentration $\left(\mathrm{mg} \mathrm{kg}^{-1}\right), C_{\mathrm{e}}$ is the solution-phase concentration $\left(\mathrm{mg} \mathrm{L}^{-1}\right), K_{\mathrm{F}}\left(\mathrm{mg} \mathrm{kg}^{-1}\right)(\mathrm{mg} / \mathrm{L})^{-N}$ is the Freundlich distribution coefficient, and $N$ is the isotherm nonlinearity factor. Single-point organic C-normalized distribution coefficients $\left(K_{\mathrm{OC}}\right)$ and distribution coefficient $\left(K_{\mathrm{d}}\right)$ were calculated at reduced concentrations $\left(\mathrm{C}_{\mathrm{r}}\right)$ of $C_{\mathrm{e}} / S_{\mathrm{w}}=$ $0.0002,0.002,0.02$, and 0.2 , where $S_{\mathrm{w}}$ is the aqueous solubility of the sorbate.

\section{RESULTS AND DISCUSSION Lipid Analyses}

The level of free-extractable lipids in the freshwaterirrigated soil was $6.3 \%$ of the total organic $C$, which is in the range reported for this fraction in soils (Stevenson, 1994; Wiesenberg et al., 2004). However, the amount of lipids extracted from the wastewater-irrigated soil was significantly higher $(11 \%$ of the total organic $\mathrm{C})$. The high content of the lipids in the wastewater-irrigated soil is believed to derive from the intensive and long-term (more than $25 \mathrm{yr}$ ) irrigation with wastewater. To evaluate the role and effect of the soil lipid composition on the sorption capabilities of the studied soils, the lipid extracts were analyzed by ${ }^{1} \mathrm{H}$ NMR and GC/MS. The ${ }^{1} \mathrm{H}$

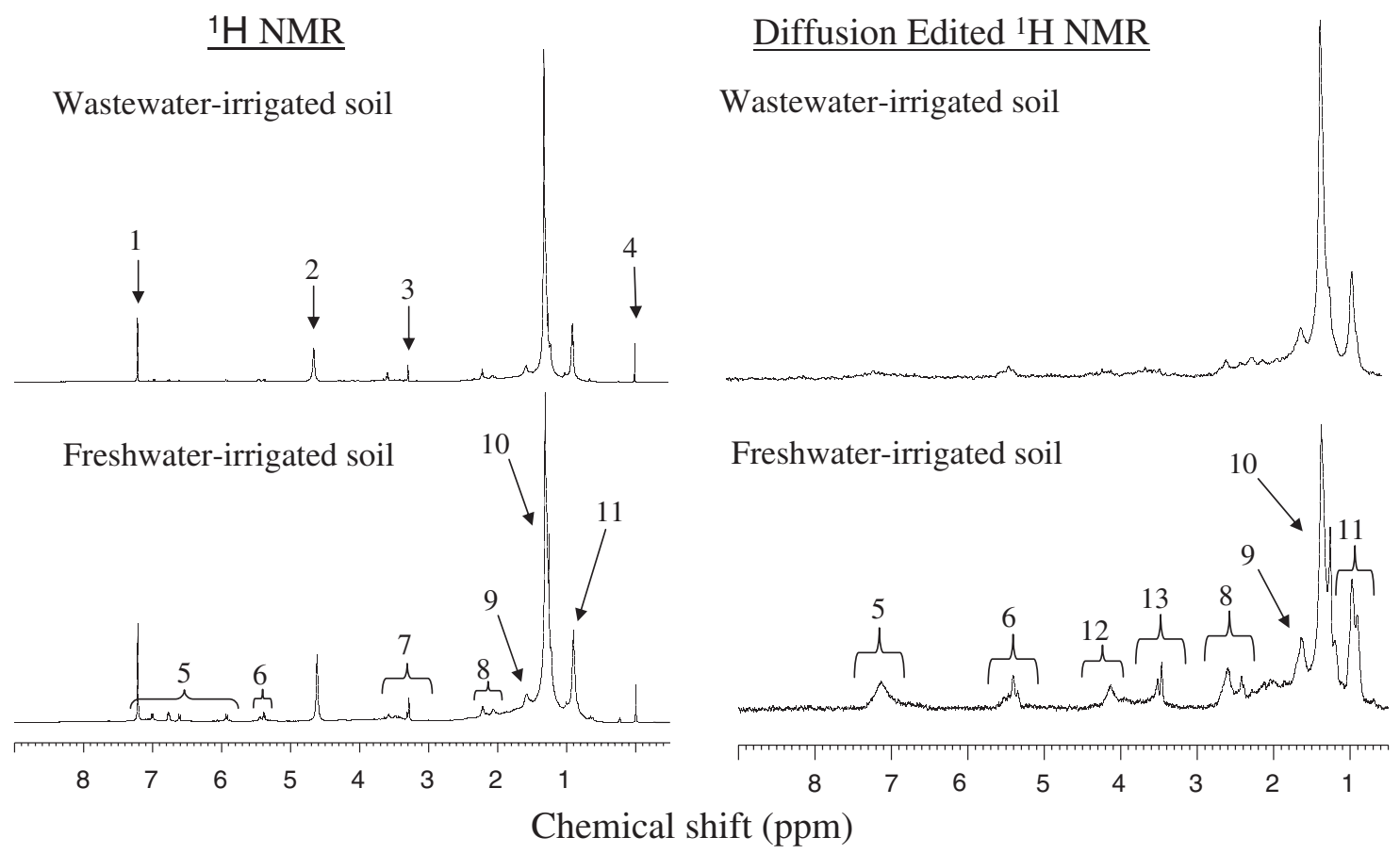

Fig. 1. ${ }^{1}$ H NMR and diffusion-edited ${ }^{1}$ H NMR spectra of the lipid extracts from wastewater- and freshwater-irrigated soils. The peaks in both spectra were assigned to benzene (1), water (2), methanol (3), tetramethylsilane (4; internal standard), aromatic and conjugated double-bond signals (5), nonconjugated double bonds (6), protons adjacent to oxygenated structures, sugars and esters, hydroxyls, ethers (7), units $\beta$ to the carbonyl in an acid or ester or $\beta$ to the double bond in an unsaturated chain (8), units $\gamma$ to an oxygen-containing linkage or double bond and methines in branched aliphatic chains (9), main-chain methylene in aliphatic chains (10), methyl protons (11), protons adjacent to oxygen in esters (12) and to ether or hydroxyls (13).
NMR spectra of the lipid extracts from both soils (Fig. 1, left side) indicated that both extracts are generally similar. The peaks in both spectra were assigned to aromatic, conjugated, and nonconjugated double bonds, protons adjacent to oxygenated structures, $\beta$ and $\gamma$ units to the carbonyl in an acid or ester, and methylene and methyl protons. Both spectra were dominated by both saturated and unsaturated aliphatic chains that are likely to be present in the form of acids, esters, and alcohols. These spectra are consistent with ${ }^{13} \mathrm{C}$ NMR spectra of soil lipids, mainly dominated by polymethylene $\mathrm{C}$ and lower levels of O-alkyl, aromatic, carbonyl, and carboxyl C functionalities (Almendros et al., 2001; Lodygin and Beznosikov, 2005).

While the type of functionalities and structural linkers in both lipid extracts were generally similar, a more detailed investigation showed some subtle differences between the two extracts, especially in the aliphatic region. The aliphatic components in the lipid extract from the freshwater-irrigated soil are less resolved and tend, in general, to have a broader line shape than these compounds in the lipid extract from the wastewaterirrigated soil. Further, the ratio of main-chain methylene $\left(\mathrm{CH}_{2}\right)$ to other functionalities and linkers (e.g., methyl groups) is smaller in the freshwater-irrigated soil's extract. The $\mathrm{CH}_{2} / \mathrm{CH}_{3}$ peak area ratio was 5 and 7.1 in the freshwater- and wastewater-irrigated soil extracts, respectively. This suggests that the aliphatic species in the lipid extract originating from the freshwater-irrigated soil contained more branched constituents and a lower

\section{$\underline{\text { Diffusion Edited }{ }^{1} \mathrm{H} \text { NMR }}$}

Wastewater-irrigated soil

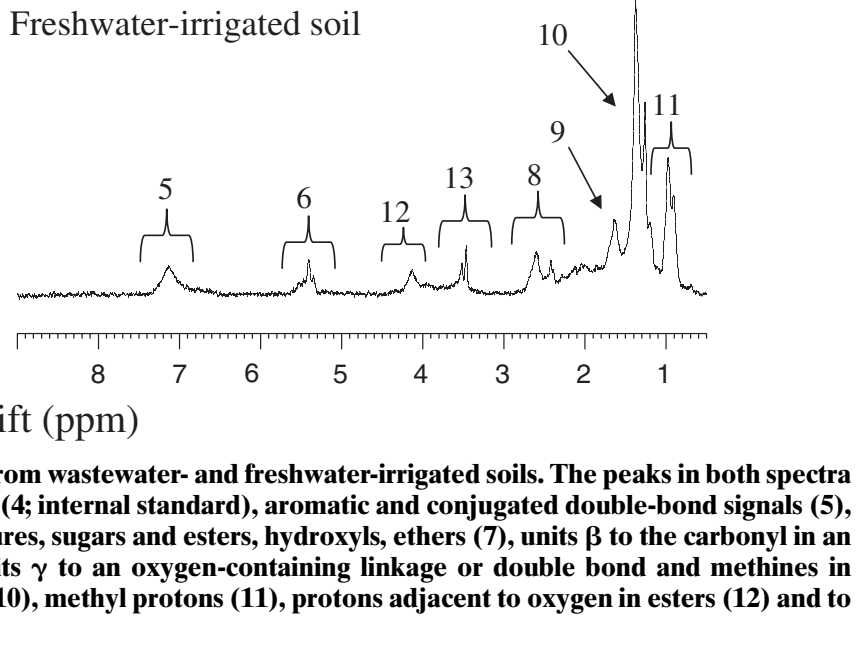


proportion of simple straight paraffinic chain species (as indicated by the lower ratio of $\mathrm{CH}_{2}$ in the freshwaterirrigated soil's extract). Conversely, in the wastewaterirrigated soil's extract, there is a higher proportion of straight-chain $\left(\mathrm{CH}_{2}\right)$ groups consistent with a high proportion of straight-chain aliphatic components in this sample.

To further investigate the properties of the two samples, we performed diffusion-edited ${ }^{1} \mathrm{H}$ NMR experiments (Fig. 1, right side). This experiment "spatially encodes" molecules at the start of the experiment and then "refocuses or decodes" them at the end of the experiment. If, during the experiment, species exhibit translational motion, they are not refocused and are essentially gated from the final spectrum. Therefore, the spectrum produced in this type of experiment contains only signals from species that undergo little or no selfdiffusion, and hence are structures in large macromolecular and/or rigid domains (Simpson et al., 2003). The diffusion-edited ${ }^{1} \mathrm{H}$ NMR spectra of the two lipid extracts were quite different. The lipid extract from the wastewater-irrigated soil was dominated by signals from $\mathrm{CH}_{2}$ and $\mathrm{CH}_{3}$, consistent with mainly straight paraffinic chain materials. In contrast, the diffusion-edited spectrum for the lipid extract from freshwater-irrigated soil exhibited strong signals from aromatics, double bonds, ester, ether, and methyl, in addition to a smaller contribution from methylene protons. Further, the broad line shape is consistent with the presence of macromolecular species in the sample. The origin of the observed species is difficult to determine although the high abundance of esters in the lipids from the freshwater-irrigated soil may indicate contributions from cuticular-derived material, whereas the aromatic species may be from suberin or lignin (Kolattukudy, 1981; Deshmukh et al., 2003). The hydrophobic nature of these compounds may lead them to preferentially concentrate in the soil lipid fraction.

The GC/MS total ion current chromatograms of the hexane fraction of the soil lipid extracts exhibited peaks assigned to alkanes and alkenes with C-chain lengths of $\mathrm{C}_{11}$ to $\mathrm{C}_{25}$ (Fig. 2). These chromatograms were similar to other reported soil-lipid-extract chromatograms (Schnitzer et al., 1986; van Bergen et al., 1997; Jandi et al., 2002; Nguyen et al., 2003). In all those chromatograms, the main peaks were suggested to originate from both plant and microbial products. The chromatogram of the lipids from the freshwater-irrigated soil exhibited a significantly higher abundance of alkenes and branched aliphatic chains. Moreover, this chromatogram overlaid a dominant unresolved-complex mixture (UCM). The UCMs are comprised of complex mixtures of isomers and homologs of branched and cyclic hydrocarbons which cannot be easily separated in a GC column (Bouloubassi and Saliot, 1993). Typically, these hydrocarbons are more resistant to biodegradation and therefore tend to accumulate in soils. The UCM in the chromatogram of the lipid extract from the freshwater-irrigated soil was centered around $\mathrm{C}_{22}$ but exhibited an additional, smaller center around $\mathrm{C}_{18}$. This bimodal UCM suggests the presence of both light and heavy lipid-derived fractions. The
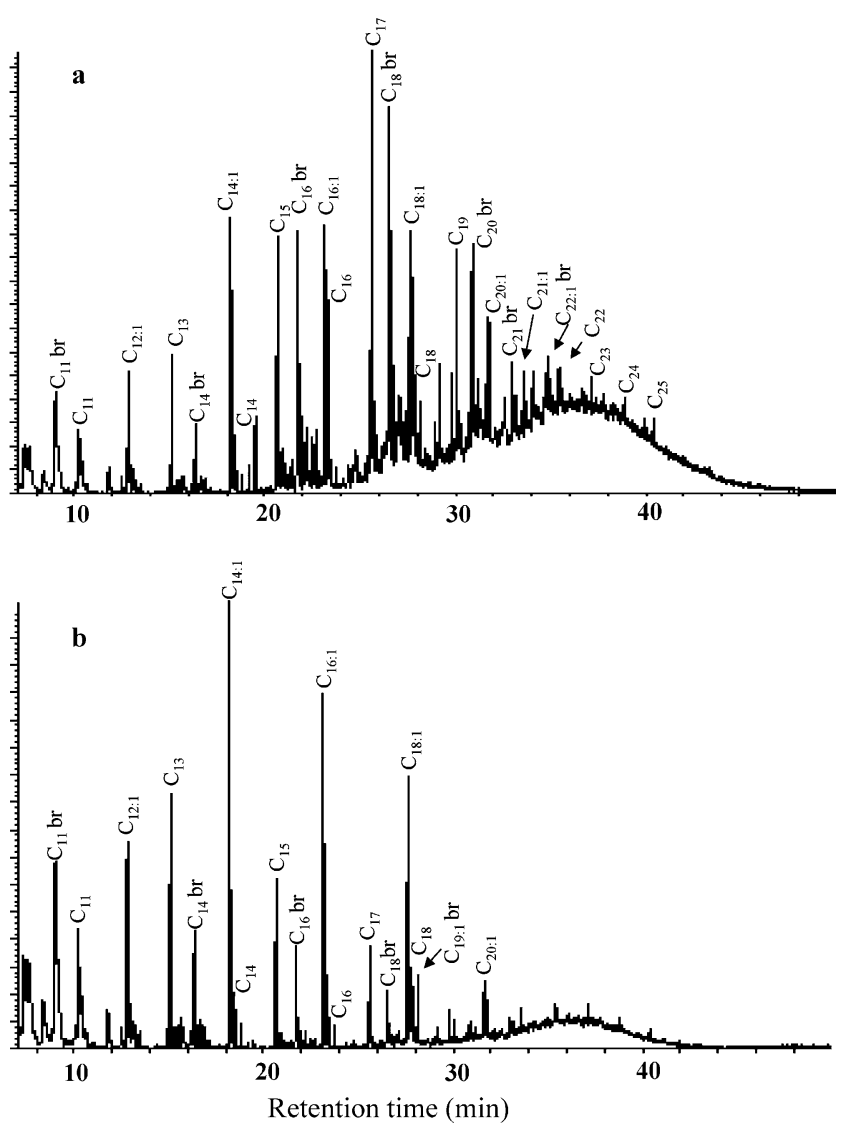

Fig. 2. Gas chromatograph/mass spectrometer (GC/MS) total ion current chromatogram of the extracted lipids (hexane fraction) from (a) freshwater-irrigated soil and (b) wastewater-irrigated soil.

UCM present in the lipid extract from the wastewaterirrigated soil chromatogram exhibited a maximum around the elution region of $\mathrm{C}_{22}$.

The freshwater-irrigated soil lipid-extract GC/MS chromatogram (Fig. 2a) exhibited a series of odd-numbered n-alkane peaks $\left(n-\mathrm{C}_{17}\right.$ to $\left.n-\mathrm{C}_{25}\right)$. This pattern $\left(>\mathrm{C}_{17}\right.$ odddominated alkanes) is traditionally assigned to epicuticular waxes of vascular plants (Schnitzer et al., 1986; Naafsa et al., 2004). In contrast, the chromatogram of the wastewater-irrigated soil (Fig. 2b) exhibited a significantly higher abundance of short-chain alkanes and alkenes $\left(<\mathrm{C}_{18}\right)$. These short-chain alkanes and alkenes could have originated from the irrigation water (i.e., wastewater) and/or from the intensive microbial activity in wastewater-irrigated soils (Pascual et al., 1997). The latter hypothesis is supported by the high abundance of short-chain alkanes that are ascribed to microbialderived lipids (Parlanti et al., 1994; Marseillea et al., 1999) and by the similar pattern of peaks in the lipid extract from sewage sludge (Reveille et al., 2003). In addition, the anthropogenic molecular marker bibenzyl (Ricking et al., 2003) was observed in the GC/MS chromatogram of the toluene fraction of the lipid extract from the wastewater-irrigated soil. This compound was not observed in the same fraction extracted from freshwater-irrigated soil. In general, the GC/MS chromatograms of the toluene fraction were poorly resolved, 
exhibiting peaks assigned to butylated hydroxytoluene, benzoic acid, and bibenzyl. All these data support the hypothesis that the shorter-chain alkanes and alkenes observed in our study probably resulted from the irrigation water (wastewater) and the associated microbial activity. In this soil (wastewater-irrigated soil), these peaks overlay the peaks originating from the vegetation.

\section{Batch Sorption Experiments}

The sorption isotherms of atrazine, chlorotoluron, and phenanthrene obtained with the freshwater- and wastewater-irrigated soils before and after lipid extraction are presented in Fig. 3. For both studied soils, lipid removal resulted in an increase in the sorption affinities $\left[K_{\mathrm{F}},\left(\mathrm{mg} \mathrm{kg}^{-1}\right)\left(\mathrm{mg} \mathrm{L}^{-1}\right)^{-N}\right]$ of all three solutes, except for phenanthrene in the wastewater-irrigated soil (Table 2).
For all solutes, this increase was noted to a lesser extent in the wastewater-irrigated soil. Since the $K_{\mathrm{F}}$ value depends on the $N$ value, it is not possible to compare the $K_{\mathrm{F}}$ values for isotherms with different $N$ values. Thus, the distribution coefficient $\left(K_{\mathrm{d}}\right)$ values were calculated for several $\mathrm{C}_{\mathrm{r}}$. With the freshwater-irrigated soil, after extraction, the $K_{\mathrm{D}}$ values of atrazine increased from 0.98 to $1.54 \mathrm{~L} \mathrm{~kg}^{-1}$ (57\% of increase) at a $\mathrm{C}_{\mathrm{r}}$ of 0.002 . This increase was noted to a lesser extent with increasing atrazine equilibrium concentration (at $0.2 C_{\mathrm{r}}, K_{\mathrm{d}}$ values increased by only $19 \%$, from 0.59 to $0.70 \mathrm{~L} \mathrm{~kg}^{-1}$ ). A significantly lower level of increase in $K_{\mathrm{d}}$ values after lipid removal was observed for the wastewater-irrigated soil. The atrazine $K_{\mathrm{d}}$ values increased from 0.86 to 1.11 and from 0.49 to $0.51 \mathrm{~L} \mathrm{~kg}^{-1}$ for $\mathrm{C}_{\mathrm{r}}$ of 0.002 and 0.2 , respectively. With chlorotoluron, a similar trend of significantly higher increases in $K_{\mathrm{d}}$ values after lipid re-
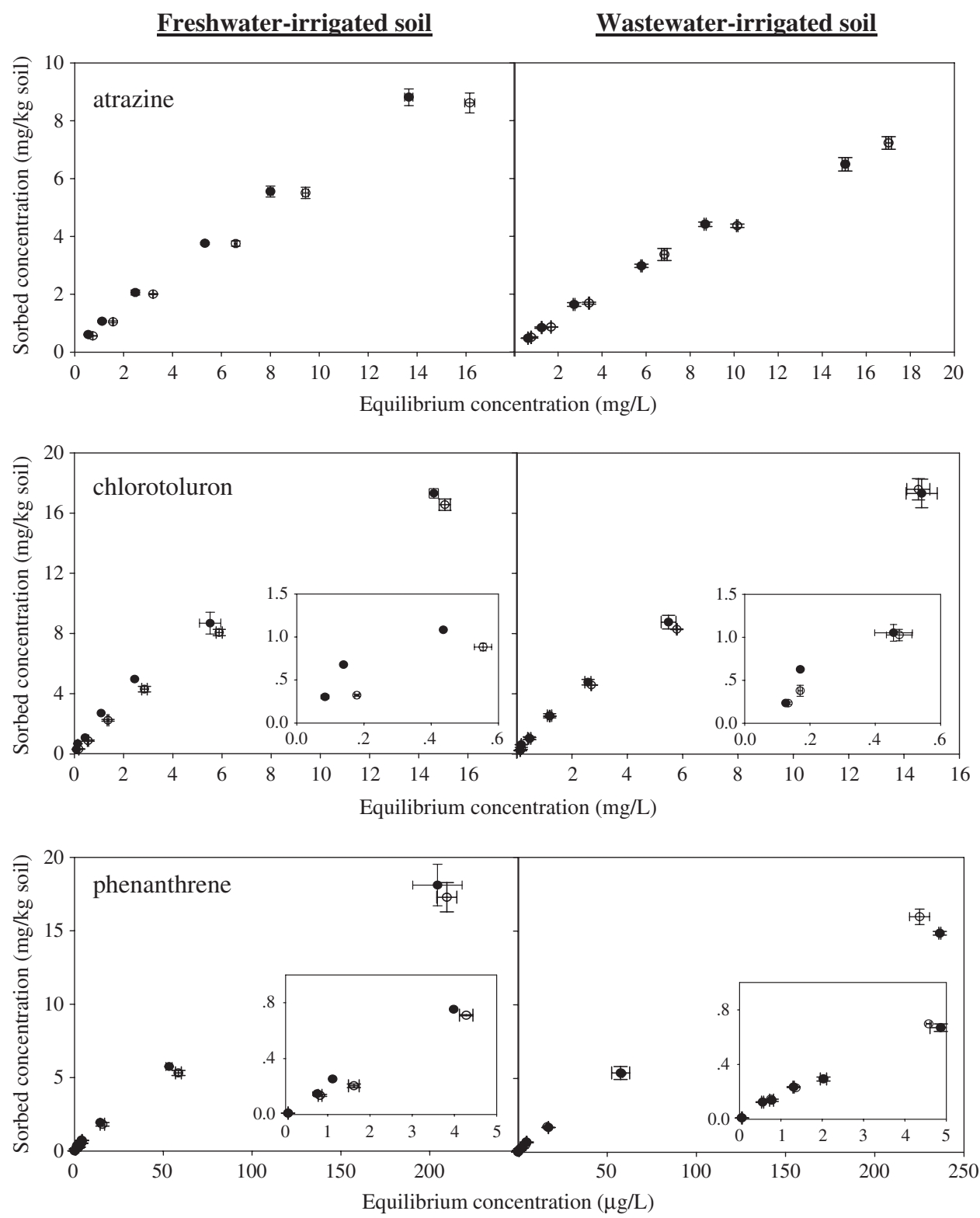

Fig. 3. Sorption isotherms of atrazine, chlorotoluron, and phenanthrene to untreated soils (open symbols) and extracted soils (filled symbols). Each point represents the mean of triplicate vials and the error bar is the range. 
Table 2. Sorption parameters calculated for the bulk and lipidextracted soils.

\begin{tabular}{cccc}
$\begin{array}{c}\text { Freshwater- } \\
\text { irrigated soil }\end{array}$ & & $\begin{array}{c}\text { Wastewater- } \\
\text { irrigated soil }\end{array}$ \\
${$\cline { 1 - 1 }$} \begin{array}{c}\text { Lipid } \\
\text { extracted }\end{array} }$ & & Untreated & $\begin{array}{c}\text { Lipid } \\
\text { extracted }\end{array}$
\end{tabular}

\begin{tabular}{|c|c|c|c|c|}
\hline \multirow{6}{*}{ 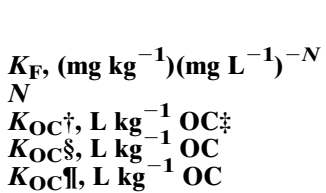 } & \multicolumn{4}{|c|}{ Atrazine } \\
\hline & 0.72 & 0.97 & 0.59 & 0.70 \\
\hline & 0.89 & 0.83 & 0.88 & 0.83 \\
\hline & 128.8 & 215.1 & 94.1 & 136.7 \\
\hline & 100.0 & 145.4 & 71.4 & 92.4 \\
\hline & 77.6 & 98.3 & 54.1 & 62.5 \\
\hline & \multicolumn{4}{|c|}{ Chlorotoluron } \\
\hline$K_{\mathrm{F}},\left(\mathrm{mg} \mathrm{kg}^{-1}\right)\left(\mathrm{mg} \mathrm{L}^{-1}\right)^{-N}$ & 1.57 & 2.48 & 1.90 & 2.23 \\
\hline & 0.90 & 0.72 & 0.86 & 0.77 \\
\hline$K_{\mathrm{OC}^{\dagger}}^{\dagger}, \mathbf{L ~ k g}_{-1}^{-1} \mathrm{OC}$ & 250.6 & 562.0 & 327.6 & 458.2 \\
\hline$K_{\mathbf{O C C}} \S, \mathbf{L ~ k g}^{-1} \mathrm{OC}$ & 199.1 & 295.0 & 237.4 & 269.8 \\
\hline \multirow[t]{2}{*}{$K_{\text {OCII, }} \mathbf{~ k g ~}^{-1} \mathrm{OC}$} & 158.1 & 154.8 & 171.9 & 158.9 \\
\hline & \multicolumn{4}{|c|}{ Phenanthrene } \\
\hline$K_{\mathrm{F}},\left(\mathrm{mg} \mathrm{kg}^{-1}\right)\left(\mathrm{mg} \mathrm{L}^{-1}\right)^{-N}$ & 78.3 & 91.8 & 62.6 & 61.7 \\
\hline & 0.91 & 0.91 & 0.87 & 0.86 \\
\hline$K_{\mathrm{OC}}^{\#,} \mathrm{~L} \mathrm{~kg}_{-1}^{-1} \mathrm{OC}$ & 22066 & 27605 & 20743 & 25006 \\
\hline$K_{\mathrm{OC}^{\dagger}}^{\dagger}, \mathbf{L ~ k g}_{-1}^{-1} \mathrm{OC}$ & 17936 & 22439 & 15377 & 18115 \\
\hline$K_{\mathrm{OC}} \S, \mathrm{L} \mathrm{kg}^{-1} \mathrm{OC}$ & 14579 & 18239 & 11399 & 13123 \\
\hline$K_{\text {OC }}$ I, $\mathbf{L ~ k g}^{-1} \mathrm{OC}$ & 11850 & 14825 & 8450 & 9507 \\
\hline
\end{tabular}

$\dagger$ Calculated at $C_{\mathrm{e}} / S_{\mathrm{w}}=0.002$ where $C_{\mathrm{e}}$ and $S_{\mathrm{w}}$ are the equilibrium concentration and aqueous solubility, respectively.

$\doteqdot \mathbf{O C}=$ organic $\mathbf{C}$.

$\S$ Calculated at $C_{\mathrm{e}} / S_{\mathrm{w}}=0.02$.

II Calculated at $C_{\mathrm{e}} / S_{\mathrm{w}}=0.2$.

\# Calculated at $C_{\mathrm{e}} / S_{\mathrm{w}}=\mathbf{0 . 0 0 0 2}$.

moval with the freshwater- vs. wastewater-irrigated soil was observed, but only at the low solute concentration $\left(\mathrm{C}_{\mathrm{r}}\right.$ of 0.002$)$. At this concentration, $K_{\mathrm{d}}$ values increased from 1.91 to 4.02 and from 2.99 to $3.73 \mathrm{~L} \mathrm{~kg}^{-1}$ for the freshwater- and wastewater-irrigated soils, respectively. At high chlorotoluron concentration $\left(\mathrm{C}_{\mathrm{r}}\right.$ of 0.2$), K_{\mathrm{d}}$ values decreased after lipid removal. With the freshwaterirrigated soil, $K_{\mathrm{d}}$ values decreased from 1.21 to $1.11 \mathrm{~L} \mathrm{~kg}^{-1}$, and for the wastewater-irrigated soil, the $K_{\mathrm{d}}$ decreased from 1.57 to $1.29 \mathrm{~L} \mathrm{~kg}^{-1}$. This behavior is related to the highly nonlinear isotherms observed for this solute after lipid removal. Freundlich $N$ values decreased from 0.90 to 0.72 and from 0.86 to 0.77 after lipid removal for the freshwater- and wastewater-irrigated soils, respectively (Table 2). With phenanthrene (the most hydrophobic solute used in this study), the $K_{\mathrm{d}}$ values exhibited a maximum increase of $17 \%$ due to lipid removal in the freshwater-irrigated soil (from 137 to 160 and from 90 to $106 \mathrm{~L} \mathrm{~kg}^{-1}$ for the $\mathrm{C}_{\mathrm{r}}$ of 0.002 and 0.2 , respectively). With the wastewater-irrigated soil, $K_{\mathrm{d}}$ values were not affected by lipid removal, similar to the unchanged $K_{\mathrm{F}}$ and $N$ values. For this soil, $K_{\mathrm{d}}$ values were 190 and $77 \mathrm{~L} \mathrm{~kg}^{-1}$ for the bulk and lipid-extracted soil at $\mathrm{C}_{\mathrm{r}}$ of 0.002 and 0.2 , respectively.

It is important to note that although the extraction (lipid removal) resulted in a significantly stronger increase in sorption affinity of the freshwater-irrigated soil compared to the wastewater-irrigated soil, the level of organic $\mathrm{C}$ removed by extraction was higher in the wastewater-irrigated soil $(11 \%)$ than in the freshwaterirrigated soil (6\%). Previous studies (Kohl and Rice, 1999; Tremblay et al., 2005) have suggested that lipid removal does not modify the surface or pore properties of geosorbents and soils. Therefore, it was concluded that the changes in the observed sorption capabilities can be assigned to changes caused mostly by the lipid removal.

In addition to the increase in sorption affinity $\left(K_{\mathrm{F}}\right.$, $K_{\mathrm{d}}$ ), lipid removal from both soils resulted in a decrease in the linearity of the isotherms of atrazine and chlorotoluron. A decrease in sorption linearity combined with an increase in sorption affinity to the sorbent (whole soil) suggest that binding sites and/or partitioning domains having high affinity for these solutes (atrazine and chlorotoluron) were probably occupied by lipids. These lipids were probably competing with atrazine and chlorotoluron for sorption domains. Since the SOM is the major sorption domain for the tested solutes, the effects of lipid removal on sorption affinity are also reported using $K_{\mathrm{OC}}$ values (Table 2). A significant increase in $K_{\text {OC }}$ values of atrazine and chlorotoluron after lipid removal was observed at low solute concentration $\left(\mathrm{C}_{\mathrm{r}}=0.002\right)$. Atrazine $K_{\mathrm{OC}}$ values increased from 128 to $251 \mathrm{~L} \mathrm{~kg}^{-1} \mathrm{OC}$ and chlorotoluron $K_{\mathrm{OC}}$ values increased from 250 to $562 \mathrm{~L} \mathrm{~kg}^{-1} \mathrm{OC}$ at this concentration. With increasing solute concentration, the level of increase in sorption affinity, weakened, similar to the trend observed for the affinities of these solutes to the whole soil ( $K_{\mathrm{d}}$ values). The effect of lipid removal was significantly higher with the freshwaterirrigated soil than with the wastewater-irrigated soil. For example, the atrazine $K_{\mathrm{OC}}$ values (at $C_{\mathrm{r}}$ of 0.002 ) increased by 70 vs. $45 \%$ for the two soils, respectively. With chlorotoluron, the $K_{\mathrm{OC}}$ values increased by $120 \%$ due to lipid removal in the freshwater-irrigated soil and by only $40 \%$ in the wastewater-irrigated soil. A similar trend but much milder was observed for phenanthrene: an increase of $25 \%$ in $K_{\mathrm{OC}}$ value as a result of lipid removal was observed for the freshwater-irrigated soil, whereas an increase of 12 to $25 \%$ was observed for the wastewaterirrigated soil counterpart at $\mathrm{C}_{\mathrm{r}}$ of 0.0002 to 0.2 .

The increase in the sorption affinity of phenanthrene as a result of lipid removal was not accompanied by a decrease in sorption linearity. This trend was in contrast to the data presented by Tremblay et al. (2005). In that study, Tremblay et al. reported a sharp (one order of magnitude) increase in the sorption affinity of phenanthrene and a sharp decrease in sorption linearity after lipid removal from geosorbents (sediment and humin). In our study, the increase in phenanthrene sorption affinity due to lipid removal was much lower than that reported by Tremblay et al. (2005) or Kohl and Rice (1999). For similar solute concentrations $\left(C_{r}\right.$ of 0.0002$)$, in our study the calculated $K_{\text {OC }}$ values for phenanthrene increased by up to $25 \%$ as a result of lipid removal. The moderate effect of lipid removal on our soils was similar to the trend reported for humic acid (Tremblay et al., 2005). Therefore it is concluded that in our bulk soils (similar to the humic acid) the partitioning domains for phenanthrene are available and are not limiting parameter for phenanthrene binding. Moreover, we assume that in our soils the lipid fraction competes for sorption sites better with organic compounds capable of polar interactions than with highly hydrophobic HOCs such as phenanthrene which have unlimited partitioning sites. 


\section{CONCLUSIONS}

Our data suggest that lipid removal induced a higher increase in sorption affinity for the solutes capable of polar interaction (i.e., atrazine and chlorotoluron) than for phenanthrene, which is capable of only nonspecific interactions. In addition, the level of increase in sorption affinities due to lipid removal was much higher for the freshwater-irrigated soil than the wastewater-irrigated soil, even though the lipid level in the freshwaterirrigated soil was half that in the wastewater-irrigated soil. These two trends (higher level of increasing affinity for the more polar solutes and for the freshwaterirrigated soil, due to lipid removal) suggests that the nature of the lipids in these two soils differs and that this affects their role and contribution to the sorption of HOCs.

The ${ }^{1} \mathrm{H}$ NMR data suggest that the lipid extract from the wastewater-irrigated soil is composed mainly of straight paraffinic chains. In contrast, the lipid extract from freshwater-irrigated soil is composed of aromatics, double bonds, ester, ether, and methyl, in addition to a smaller contribution from methylene protons. Further, the latter sample contained a rigid macromolecular-like material that showed little translational diffusion and contained significant contributions from esters, ethers/ hydroxyl, and aromatic units alongside the dominant aliphatic signal. Our GC/MS data support these findings, showing a higher abundance of branched, longer paraffinic chains and bimodal UCMs in the freshwaterirrigated soil's extract than in the extract from the wastewater-irrigated soil. The greater contribution from polar functionalities such as ether and ester moieties in the lipid fraction from the freshwater-irrigated soil suggests that these extractable compounds successfully compete with the polar solutes (atrazine and chlorotoluron) for binding sites in the SOM. The sites which have been newly exposed by the lipid removal are suggested to be of a relatively polar nature.

\section{ACKNOWLEDGMENTS}

This research was supported by research grant (821-008704) from the Israeli Ministry of Agriculture. The authors also thank the anonymous reviewers whose suggestions improved this paper.

\section{REFERENCES}

Almendros, G., P. Tinoco, F.J. Gonzales-Vila, H.-D. Lüdemann, J. Sanz, and F. Velasco. 2001. ${ }^{13} \mathrm{C}$ NMR of forest soil lipids. Soil Sci. 166: 186-196.

Bouloubassi, I., and A. Saliot. 1993. Investigation of anthropogenic and natural organic inputs in estuarine sediments using hydrocarbon markers (NAH, LAB, PAH). Oceanol. Acta 16:145-161.

Boyd, S.A., and L.E. Sommers. 1990. Humic and fulvic acid fractions from sewage sludges and sludge-amended soils. p. 203-220. In P. MacCarthy et al. (ed.) Humic substances in soil and crop sciences: Selected readings. ASA, Madison, WI.

Bull, I.D., P.F.V. Bergen, C.J. Nott, P.R. Poulton, and R.P. Evershed. 2000. Organic geochemical studies of soils from the Rothamsted classical experiments: V. The fate of lipids in different long-term experiments. Org. Geochem. 31:389-408.

Deshmukh, A.P., A.J. Simpson, and P.G. Hatcher. 2003. Evidence for cross-linking in tomato cutin using HR-MAS NMR spectroscopy. Phytochemistry 64:1163-1170.
Drori, Y., Z. Aizenshtat, and B. Chefetz. 2005. Sorption-desorption behavior of atrazine in soils irrigated with reclaimed wastewater. Soil Sci. Soc. Am. J. 69:1703-1710.

Friedel, J.K., T. Langer, C. Siebe, and K. Stahr. 2000. Effects of longterm waste water irrigation on soil organic matter, soil microbial biomass and its activities in central Mexico. Biol. Fertil. Soils 31: 414-421.

Gee, G.W., and J.W. Bauder. 2002. Particle size analysis, p. 278-284. In J.H. Dane and G.C. Topp (ed.) Methods of soil analysis. Part 4. SSSA Book Ser. 5. SSSA, Madison, WI.

Gonzalez-Vila, F.J., T. Verdejo, J.C. Del Rio, and F. Martin. 1995. Accumulation of hydrophobic compounds in the soil lipidic and humic fractions as result of a long term land treatment with olive oil mill effluents (alpechin). Chemosphere 31:3681-3686.

Grathwohl, P. 1990. Influence of organic matter from soils and sediments from various origins on the sorption of some chlorinated aliphatic hydrocarbons: Implications on Koc correlations. Environ. Sci. Technol. 24:1687-1693.

Guichet, J., P. Jambu, and H. Dinel. 1991. Changes in the organic matter of a rendzina soil caused by wastewater sludge disposals from dairy processing plants. Pedologie 41:149-162.

Jandi, G., H.-R. Schulten, and P. Leinweber. 2002. Quantification of long-chain fatty acids in dissolved organic matter and soils. J. Plant Nutr. Soil Sci. 165:133-139.

Kohl, S.D., and J.A. Rice. 1999. Contribution of lipids to the nonlinear sorption of polycyclic aromatic hydrocarbons to soil organic matter. Org. Geochem. 30:929-936.

Kohl, S.D., J.P. Toscano, W. Hou, and J.A. Rice. 2000. Solid-state ${ }^{19}$ F NMR investigation of hexafluorobenzene sorption to soil organic matter. Environ. Sci. Technol. 34:204-210.

Kolattukudy, P.E. 1981. Structure, biosynthesis, and biodegradation of cutin and suberin. Annu. Rev. Plant Physiol. 32:539-567.

Lodygin, E.D., and V.A. Beznosikov. 2005. Influence of soil moisture on concentrations and ${ }^{13} \mathrm{C}$ NMR profiles of lipids in three albeluvisols. Geoderma 127:253-262.

Loepert, R.H., and D.L. Suarez. 1996. Carbonate and gypsum. p. 440-444. In D.L. Sparks (ed.) Methods of soil analysis. Part 3 SSSA Book Ser. 5. SSSA, Madison, WI.

Marseillea, F., J.R. Disnara, B. Guilleta, and Y. Noackb. 1999. nAlkanes and free fatty acids in humus and A1 horizons of soils under beech, spruce and grass in the Massif-Central (Mont-Lozere), France. Eur. J. Soil Sci. 50:433-441.

Naafsa, D.F.W., P.F. van Bergen, M.A. de Jonga, A. Oonincxa, and J.W. de Leeuwa. 2004. Total lipid extracts from characteristic soil horizons in a podzol profile. Eur. J. Soil Sci. 55:657-669.

Nelson, D.W., and L.E. Sommers. 1996. Total carbon, organic carbon and organic matter. p. 965-971. In D.L. Sparks (ed.) Methods of soil analysis. Part 3. SSSA Book Ser. 5. SSSA, Madison, WI.

Nguyen, T.T., S. Derenne, C. Largeau, A. Mariotti, and H. Bocherens. 2003. Comparison of leaf lipids from a fossil ginkgoalean plant and its extant counterpart at two degradation stages: Diagenetic and chemotaxonomic implications. Rev. Palaeobot. Palynol. 124: 63-78.

Parlanti, E., C. Hita, P. Jambu, H. Dinel, and A. Ambles. 1994. The internal double-bond insertion: A side reaction of aliphatic hydrocarbons degradation in soil. Soil Biol. Biochem. 26:1375-1378.

Pascual, J.A., C. Garcia, T. Hernandez, and M. Ayuso. 1997. Changes in the microbial activity of an arid soil amended with urban organic wastes. Biol. Fertil. Soils 24:429-434.

Pennel, K.D. 2002. Specific surface area. p. 308-313. In J.H. Dane and G.C. Topp (ed.) Methods of soil analysis. Part 4. SSSA Book Ser. 5. SSSA, Madison, WI.

Reveille, V., L. Mansuy, E. Jarde, and E. Garnier-Sillam. 2003. Characterisation of sewage sludge-derived organic matter: Lipids and humic acids. Org. Geochem. 34:615-627.

Ricking, M., J. Schwarzbauer, and S. Franke. 2003. Molecular markers of anthropogenic activity in sediments of the Havel and Spree rivers (Germany). Water Res. 37:2607-2617.

Schnitzer, M., C.A. Hindle, and M. Meglic. 1986. Supercritical gas extraction of alkanes and alkanoic acids from soil and humic material. Soil Sci. Soc. Am. J. 50:913-919.

Simpson, A.J., X. Zang, R. Kramer, and P.G. Hatcher. 2003. New insights on the structure of algaenan from Botryoccocus braunii race $\mathrm{A}$ and its hexane insoluble botryals based on multidimensional 
NMR spectroscopy and electrospray-mass spectrometry techniques. Phytochemistry 62:783-796.

Stevenson, F.J. 1994. Humus chemistry: Genesis, composition, reactions. 2nd ed. John Wiley \& Sons, New York.

Sumner, M.E., and W.P. Miller. 1996. Cation exchange capacity and exchange coefficients. p. 1220-1221. In D.L. Sparks (ed.) Methods of soil analysis. Part 3. SSSA Book Ser. 5. SSSA, Madison, WI.

Tarchitzky, J., Y. Golobati, R. Keren, and Y. Chen. 1999. Wastewater effects on montmorillonite suspensions and hydraulic properties of sandy soils. Soil Sci. Soc. Am. J. 63:554-560.

Tremblay, L., S.D. Kohl, J.A. Rice, and J.-P. Gagne. 2005. Effects of lipids on the sorption of hydrophobic organic compounds on geosorbents: A case study using phenanthrene. Chemosphere 58:1609-1620.

van Bergen, P.F., I.D. Bull, P.R. Poulton, and R.P. Evershed. 1997.
Organic geochemical studies of soils from the Rothamsted classical experiments: I. Total lipid extracts, solvent insoluble residues and humic acids from Broadbalk Wilderness. Org. Geochem. 26: 117-135.

Wiesenberg, G.L.B., L. Schwark, and M.W.I. Schmidt. 2004. Improved automated extraction and separation procedure for soil lipid analyses. Eur. J. Soil Sci. 55:349-356.

Wu, D., A. Chen, and C.S. Johnson, Jr. 1995. An improved diffusionordered spectroscopy experiment incorporating bipolar-gradient pulses. J. Magn. Reson. Ser. A 115:260-264.

Zech, W., N. Senesi, G. Guggenberger, K. Kaiser, J. Lehmann, T.M. Miano, A. Miltner, and G. Schroth. 1997. Factors controlling humification and mineralization of soil organic matter in the tropics. Geoderma 79:117-161. 